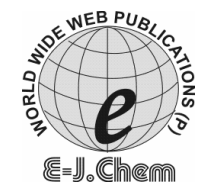

http://www.e-journals.net
ISSN: 0973-4945; CODEN ECJHAO

E-Journal of Chemistry

Vol. 5, No.3, pp. 427-430, July 2008

\title{
High Performance Thin Layer Chromatographic Method for Estimation of Cefprozil in Tablet Dosage Form
}

\author{
V. JAGAPATHI RAJU and J. V. L. N. SESHAGIRI RAO* \\ University College of Pharmaceutical Sciences, \\ Andhra University, Visakhapatnam -530003, India. \\ jvlnsrao@gmail.com
}

Received 19 May 2007; Accepted 10 July 2007

\begin{abstract}
A simple, fast, specific and precise HPTLC method has been developed for the estimation of cefprozil in pure and in tablet dosage forms. Aluminium plates precoated with silica gel $\mathrm{G}_{60} \mathrm{~F}_{254}$ were used as stationary phase and a mixture of chloroform: methanol: toluene: diethyl amine: water in the ratio 4: 4.4: 3.2: $3: 0.8 \mathrm{v} / \mathrm{v}$ as mobile phase. Quantification was carried out by the use of a densitometer in absorbance mode at $286 \mathrm{~nm}$. The $\mathrm{R}_{\mathrm{f}}$ value of cefprozil was found to be between 0.37 and 0.40 . The results of the analysis have been validated statistically and by recovery studies. Linearity was observed in the concentration range of 400-2000 ng/spot.
\end{abstract}

Keywords: Cefprozil, Estimation in tablets, HPTLC.

\section{Introduction}

Cefprozil is chemically (6R, 7R)-7-((R)-2-amino-2-(p-hydroxy-phenyl) acetamido) -8-oxo-3propenyl-5-thia-1-azabicyclo (4.2.0) oct-2-ene-2-carboxylic acid. It is a semi synthetic oral second generation cephalosporin consisting of 9:1 Z/E isomeric mixture with a wide antibacterial spectrum of activity. Literature survey reveals HPLC method for the simultaneous determination of cefprozil diasteriomers ${ }^{3}$, flow injection chemiluminescent determination of cefprozil $^{2}$, spectrophotometric determinations $s^{4,5}$ and spectrofluorimetric determinations ${ }^{6,7}$. As there is no HPTLC method at present the author's propose a precise and accurate HPTLC method for the estimation of Cefprozil in pure and in tablet dosage forms.

\section{Experimental}

\section{Instrumentation}

A Camag HPTLC system comprising of a Linomat-5 applicator and Camag TLC scanner-3 with Wincats 4 software for interpretation of data along with a single pan balance of Mettler-toledo model was used, for the present study. Dissolution of the compounds was enhanced by sonication on a Bandelin sonerex sonicator. 


\section{Drugs and chemicals}

The authenticity and purity of cefprozil USP was certified by Aurobindo pharma Ltd as 98.5\% w/w. Refzil-O tablets (Ranbaxy pharma) containing $250 \mathrm{mg}$ of cefprozil USP were procured from the local market. Purified water was prepared using a Millipore Milli-Q (Bedford, M.A., USA) water purification system. chloroform, methanol, toluene and diethyl amine procured from Merck Ltd. (Mumbai, India) were used in the study.

\section{Chromatographic conditions}

Stationary phase used was aluminium plates precoated with silica gel G $60 \mathrm{~F}_{254}(20 \mathrm{~cm} \mathrm{x10} \mathrm{cm})$. Mobile phase used in the study was a mixture of chloroform: methanol: toluene: diethyl amine: water in the ratio 4: 4.4: $3.2: 3: 0.8 \mathrm{v} / \mathrm{v}$. Development chamber used was a Camag twin trough glass chamber $(20 \mathrm{~cm} \times 10 \mathrm{~cm})$ saturated with filter paper for 10 mins. Separation was carried out by ascending development. The size of the plate used was $20 \times 10 \mathrm{~cm}$. Sample application position on plate was at $10 \mathrm{~mm}$ distance from the base and solvent front was developed to $80 \mathrm{~mm}$. Band of length $8 \mathrm{~mm}$ was applied. Deuterium lamp was used and UV detection was carried out at $286 \mathrm{~nm}$. The scanning speed used was $20 \mathrm{~mm} / \mathrm{sec}$.

\section{Preparation of standard solution}

It is prepared by accurately weighing and transferring $100 \mathrm{mg}$ of cefprozil into a $100 \mathrm{~mL}$ volumetric flask and making to volume using $10 \mathrm{~mL}$ water and $90 \mathrm{~mL}$ methanol. The resulting solution A has a concentration of $1 \mathrm{mg} / \mathrm{mL}$. $2 \mathrm{~mL}$ of solution A is made up to 10 $\mathrm{mL}$ with methanol to give standard stock solution of concentration $0.2 \mathrm{mg} / \mathrm{mL}$ or $0.2 \mu \mathrm{g} / \mu \mathrm{L}$.

\section{Results and Discussion}

\section{Linearity and calibration}

Standard stock solutions of 2, 4, 6, 8 and $10 \mu \mathrm{L}$ were applied on a TLC plate with the help of a Camag Linomat-5 sample applicator to give concentrations of 400, 800, 1200, 1600 and 2000 $\mathrm{ng} / \mathrm{spot}$. The developing chamber was allowed to saturate with mobile phase using a filter paper. The mobile phase was then used for separation of components by ascending development method. After development the plate was removed from the chamber and dried using hot air. The bands were evaluated at $286 \mathrm{~nm}$. A typical HPTLC densitogram of cefprozil standard is shown in Figure 1. The values obtained for the calibration curve are shown in Table 2.

\section{Estimation of cefprozil in tablets}

Twenty tablets were weighed and finely powdered. Accurately weighed quantity of tablet powder equivalent to about $10 \mathrm{mg}$ of cefprozil was transferred to a $10 \mathrm{~mL}$ volumetric flask, added $1 \mathrm{~mL}$ of $\mathrm{H}_{2} \mathrm{O}$ and shaken for 5 minutes. The volume was then made up to mark with methanol. The solution was filtered through Whatmann filter paper and the filtrate was appropriately diluted with methanol to get a final concentration of $600 \mathrm{ng} / \mathrm{spot}$ of Cefprozil. The resulting solution was used for analysis. Chromatograms were obtained by maintaining the above said chromatographic conditions and evaluation was performed using densitogram area. The results are shown in Table 1.

Table 1. Estimation of cefprozil in tablets

\begin{tabular}{cc}
\hline Label claim, mg/tab & Amount found (area), mg/tab \\
\hline & 245 \\
250 & 249 \\
& 251 \\
Mean & 255 \\
RSD & 252 \\
\end{tabular}


Table 2. Calibration of the HPTLC method for the estimation of cefprozil

\begin{tabular}{cc}
\hline Conc, $\mathrm{ng} / \mathrm{spot}$ & Densitogram area \\
\hline 400 & 1954.5 \\
800 & 3639.6 \\
1200 & 5079.5 \\
1600 & 6010.5 \\
2000 & 7018.5 \\
\hline sion equation from $400-2000 \mathrm{ng} /$ spot,$Y=3.234 X+880\left(r^{2}=0.9997\right)$
\end{tabular}

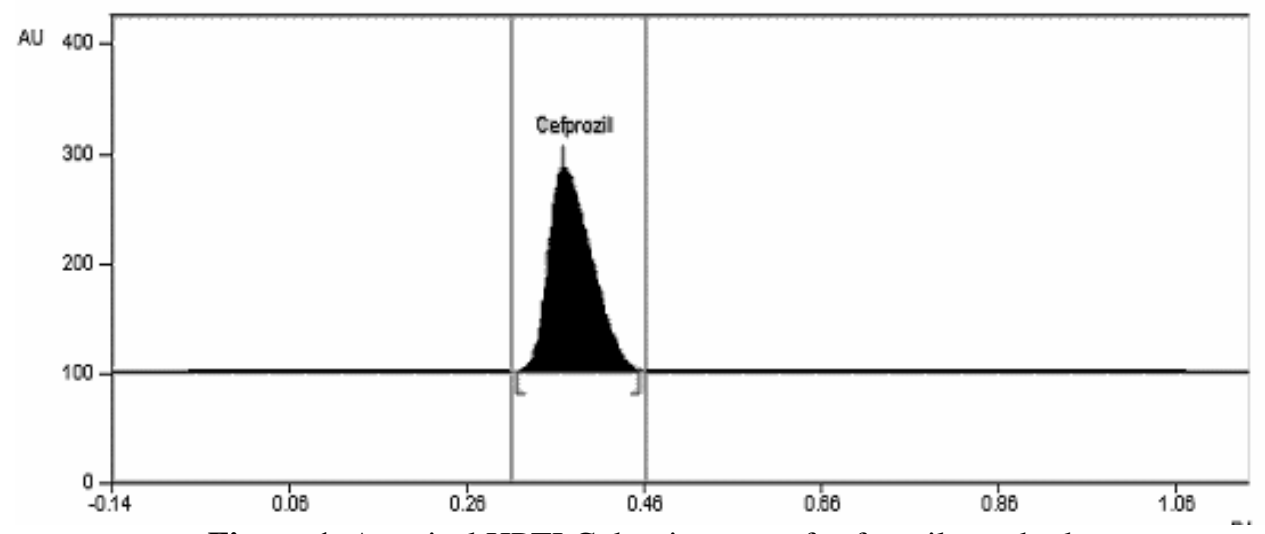

Figure 1. A typical HPTLC densitogram of cefprozil standard

The Rf values were determined and found to be in the range of $0.37-0.40$.

\section{Recovery studies}

To ensure the reliability of method recovery studies were carried out by mixing a known quantity of standard drug with preanalysed sample and contents were reanalyzed by proposed method. The values are given in Table 3.

Table 3. Results of recovery study

\begin{tabular}{ccccc}
\hline Drug & $\begin{array}{c}\text { Amount of standard } \\
\text { drug added, } \mu \mathrm{g} / \mathrm{mL}\end{array}$ & $\begin{array}{c}\text { Amount of } \\
\text { drug recovered, } \mu \mathrm{g} / \mathrm{mL}\end{array}$ & \%Recovery & Mean recovery \\
\hline Cefprozil & 400 & 415.6 & 103.9 & 102.7 \\
Cefprozil & 800 & 812.0 & 101.5 & 102 \\
\hline
\end{tabular}

Specificity

The specificity was also confirmed by overlaying the spectra of standard Cefprozil with the spectra of sample recorded on TLC scanner in UV range as shown in Figure 2. The various statistical parameters and the method validation parameters were shown in Table $4 \& 5$.

Table 4. Statistical parameters.

\begin{tabular}{lc}
\hline \multicolumn{1}{c}{ Parameter } & Value \\
\hline Correlation coefficient & 0.9997 \\
Coefficient of variation $(\mathrm{C} . \mathrm{V}), \%$ & 0.515 \\
Slope $(\mathrm{a})$ & 3.234 \\
Intercept(b) & 880 \\
Regression equation & $\mathrm{Y}=3.234 \mathrm{X}+880$ \\
(Y=aX+b) & \\
axis (densitogram area). $X=X$ axis (Concentration of drug in $\mathrm{ng} /$ spot).
\end{tabular}


Figure 2. Overlay absorption spectra of Standard cefprozil \& cefprozil from tablets

Table 5. Method validation parameters

\section{Conclusion}

\begin{tabular}{ll}
\hline \multicolumn{1}{c}{ Parameter } & \multicolumn{1}{c}{ Value } \\
\hline Accuracy, $\%,($ Area $)$ & $101.04 \pm 1.78$ \\
Linearity range, ng/spot & $400-2000, \mathrm{ng} / \mathrm{spot}$ \\
Limit of detection & $133, \mathrm{ng} / \mathrm{spot}$ \\
Limit of quantification & $400, \mathrm{ng} / \mathrm{spot}$ \\
\hline
\end{tabular}

The proposed HPTLC method was precise, accurate and selective. The method was rapid, sensitive, reproducible and economical. It does not suffer any positive or negative interference due to common excipients present in formulations and can be conveniently used for routine quality control analysis.

\section{Acknowledgements}

The authors are thankful to M/s Aurobindo Pharma Limited., Hyderabad for providing pure standard of Cefprozil and M/s Anchrom enterprises (I) Pvt. Ltd., for providing HPTLC facility.

\section{References}

1. Reddy S S, Dasandi B, Patel C and Bhat K M, Indian Drugs, 2004, 41(2), 86.

2. Alarfaj N A and Abd El-Razeq S A, J. Pharm. Biomed. Anal., 2006, 41, 1423.

3. Park T, Kim J, Jee J, Park J and Kim C, J. Pharm. Biomed. Anal., 2004, 36, 243.

4. Salem H and Saleh G A, J. Pharm. Biomed. Anal., 2002, 28, 1205.

5. Salem H, Analytica Chimica Acta, 2004, 515, 333.

6. El Walily A M, Gazy A A, Belal S F and Khamis E F, J. Pharm. Biomed. Anal., 1999, 20(4), 643.

7. Yang J, Zhou G, Jie N, Han R, Lin C and Hu J, Analytica Chimica Acta, 1996, 325(3), 195. 


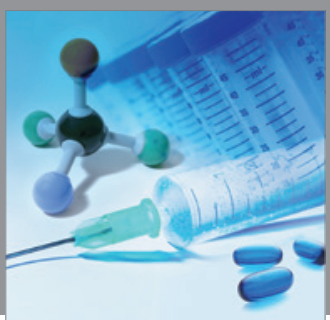

International Journal of

Medicinal Chemistry

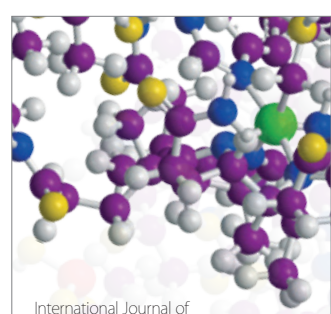

Carbohydrate Chemistry

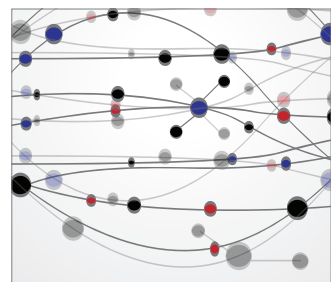

The Scientific World Journal
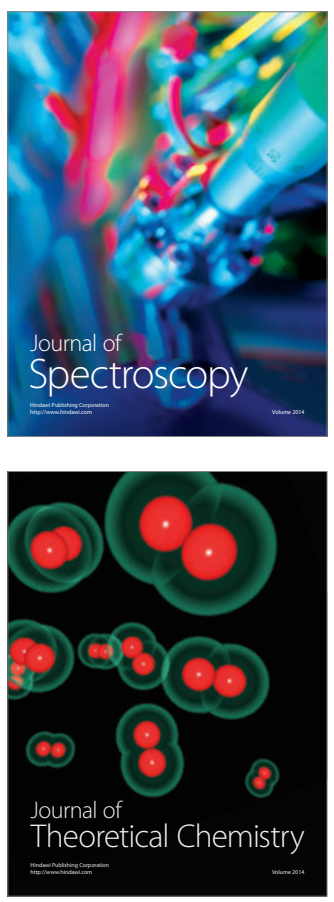
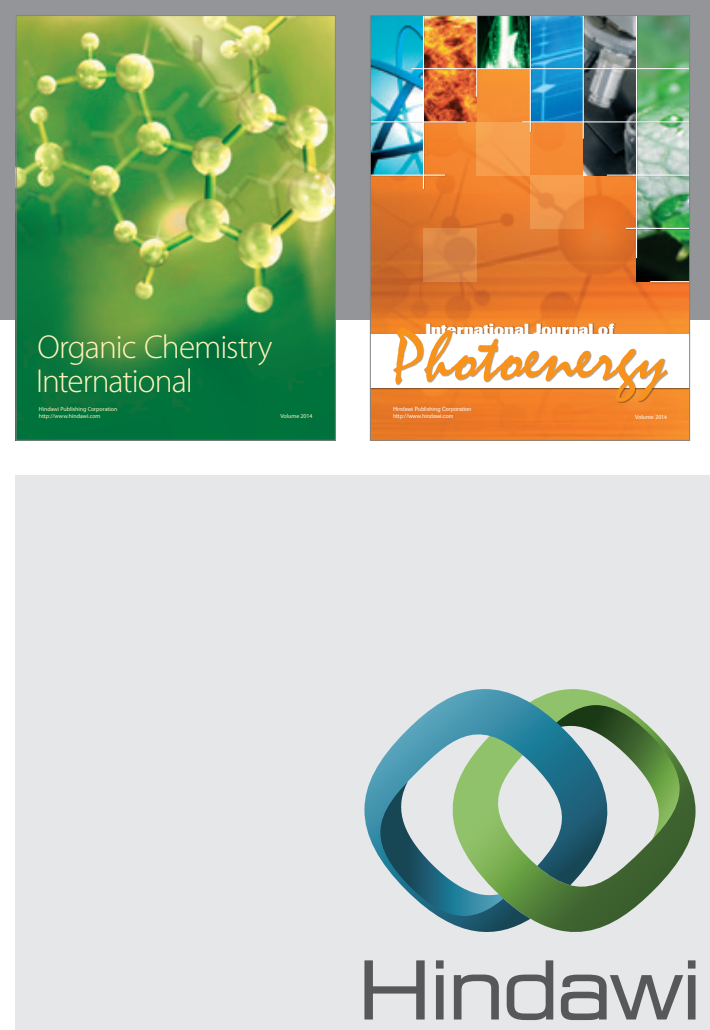

Submit your manuscripts at

http://www.hindawi.com
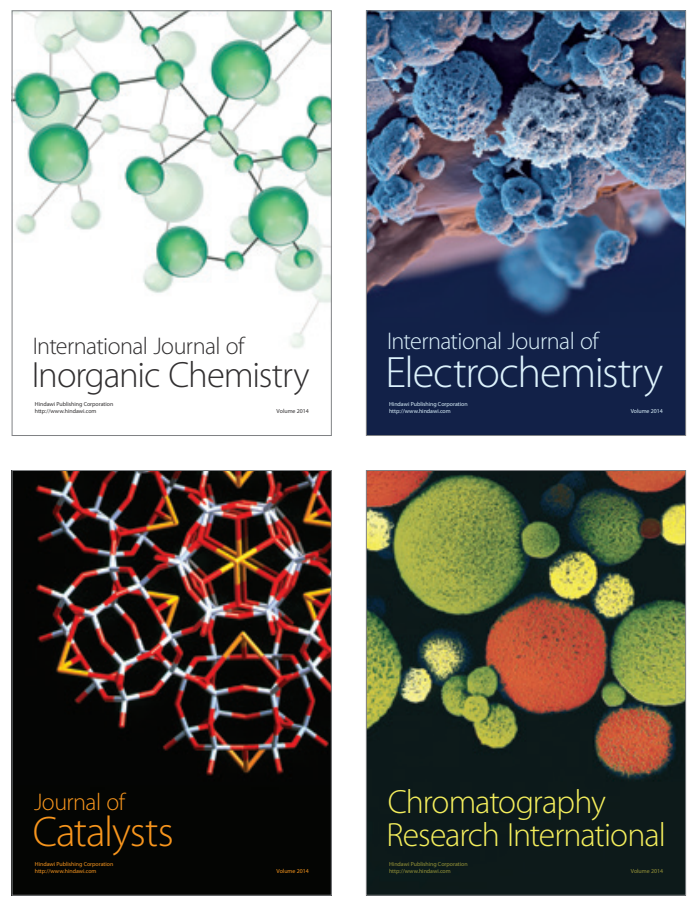
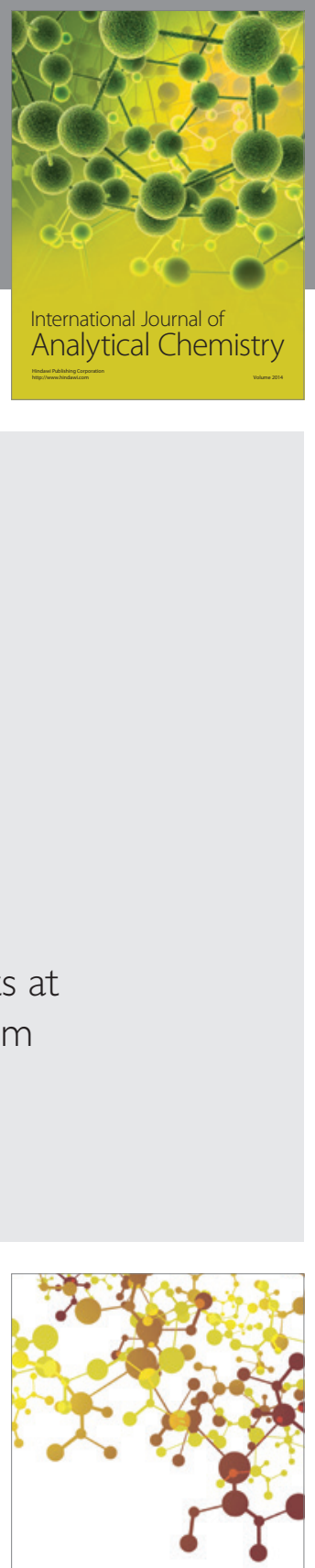

Journal of

Applied Chemistry
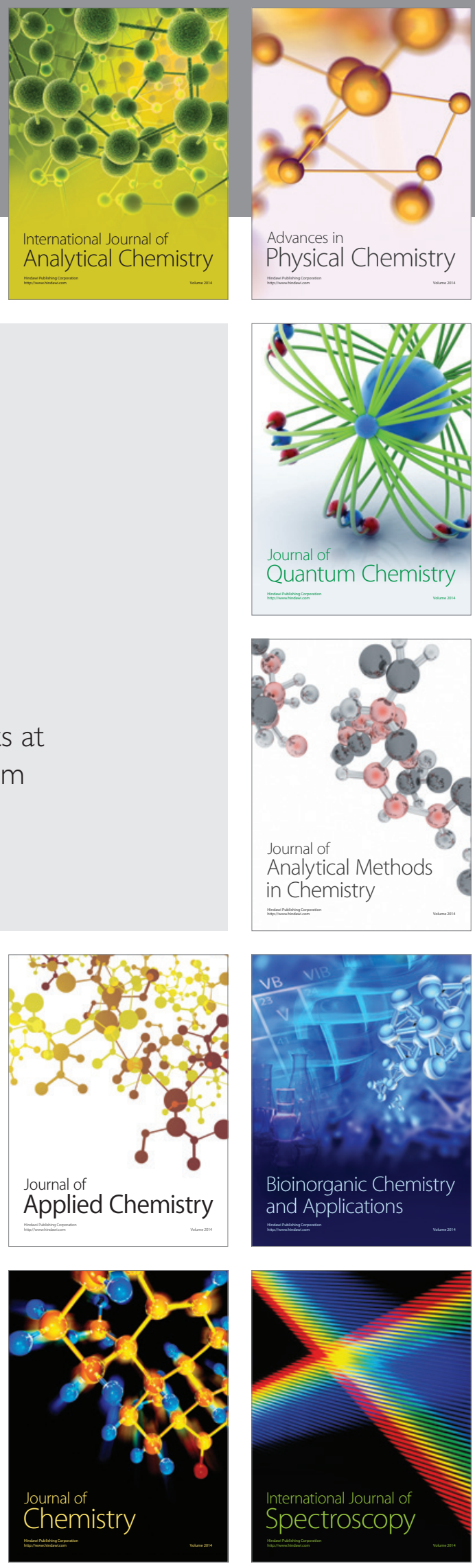